sprayed onto young bracken fronds but only when nutrient $(2 \%$ malt broth) is supplied with the inoculum and the relative humidity of the growth chamber is maintained at $100 \%$. Infection at lower relative humidity can be achieved by applying the inoculum in a mixture of dilute herbicide (ioxynil), a 'sticker' (glycerol), and nutrient ( $2 \%$ malt broth).

A disease of bracken in the U.S.A. is caused by a species of Ascochyta. The pathogenicity of this fungus to bracken in Britain is to be investigated.

The work is supported by a grant from the Agricultural Research Council.

\title{
Pteridium aquilinum: weed or resource?
}

\section{T. V. Callaghan}

Institute of Terrestrial Ecology, Natural Environmental Research Council, Merlewood Research Station, Grange-over-Sands, Cumbria LA11 6JU, U.K.

and

\section{E. Sheffield}

Department of Botany, University of Manchester, Manchester M13 9PL, U.K.

The Institute of Terrestrial Ecology has completed a survey of plant production in the U.K. and assessed the potential biomass resource. This is equivalent to $33 \%$ of U.K. energy demand. Biomass within the U.K. could therefore save $£ 1$ billion in oil imports by 2,000 A.D. Natural vegetation could be an important source of biofuels, although not all is harvestable (a contribution of $10 \%$ seems realistic). Many types of natural vegetation are extensive and productive but are not utilised; bracken, for example, covers $3,220 \mathrm{~km}^{2}$ of Great Britain and can reach above-ground productivity of $14 \mathrm{t} / \mathrm{ha} / \mathrm{yr}$. Farmers pay $£ 120$ per hectare to get rid of it at present, but, instead of using herbicides, they could be using it as an energy crop. Bracken gives high yields consistently between sites and years, and conventional harvesting equipment can be used for collection in some sites. Autumn harvesting allows retranslocation of nutrients to rhizomes and affects regrowth less than summer harvesting. Densification of autumn harvest yields a high grade fuel, while gasification or anaerobic digestion of summer harvest yield methanol or methane respectively. Densification yields briquettes suitable for domestic consumption (direct burning) and, together with gasification and anaerobic digestion products, could stimulate rural economies. Realistic costings give a price per barrel of oil equivalent (currently approximately $£ 35$ ) of $£ 12.02$ for briquettes, $£ 41.72$ for methanol and $£ 65.36$ for methane. Bracken can therefore be viewed as a valuable resource rather than a weed, and research is about to commence in the area of control of bud dormancy as part of a continuing programme of bracken utilisation.

This work was funded by the U.K. Department of Energy. Continuing research is funded also by the European Commission and at Manchester University by N.E.R.C. 